\title{
Impact of Health Insurance on Health Care Utilisation and Out-of-Pocket Health Expenditure in Vietnam
}

\author{
Nguyen Thi Thu Thuong ${ }^{(D,}$, Tran Quang Huy, Do Anh Tai, and Tran Nhuan Kien
}

TNU-University of Economics and Business Administration, Vietnam Thai Nguyen 250000

Correspondence should be addressed to Nguyen Thi Thu Thuong; nttthuong@tueba.edu.vn

Received 24 February 2020; Revised 13 July 2020; Accepted 5 August 2020; Published 26 August 2020

Academic Editor: Reinie Cordier

Copyright (c) 2020 Nguyen Thi Thu Thuong et al. This is an open access article distributed under the Creative Commons Attribution License, which permits unrestricted use, distribution, and reproduction in any medium, provided the original work is properly cited.

Background. In recent years, health insurance (HI) has been chosen by many low- and middle-income countries to obtain an important health policy target-universal health coverage. Vietnam has recently introduced the Revised Health Insurance Law, and the effects of the voluntary health insurance (VHI) and heavily subsidised health insurance (HSHI) programmes have not yet been analysed. Therefore, this study is aimed at examining the impact of these HI programmes on the utilisation of health care services and out-of-pocket health expenditure (OOP) in general and across different health care providers in particular. Methods. Using the two waves of Vietnam Household Living Standard Surveys 2014 and 2016 and the difference-in-difference method, the impacts of VHI and HSHI on health care utilisation and OOP in Vietnam were estimated. Results. For both the VHI and HSHI groups, we found that HI increased the probability of seeking outpatient care, the mean number of outpatient visits, the total number of visits, and the mean number of visits at the district level of health care providers in the last 12 months. However, there was no evidence that the HSHI programmes increased the mean number of inpatient visits and the number of visits at the provincial hospital. We also found that while the VHI programme reduced OOP for both outpatient and inpatient care, the HSHI scheme did not result in a reduction in OOP for hospitalisation, although HI lowered the total OOP. Similarly, we found that for both groups, HI reduced OOP when the insured visited district and provincial hospitals. However, the statistically significant impact was not demonstrated when the enrolees of HSHI programmes visited provincial hospitals. Conclusion. The study offers evidence that the Vietnamese HI scheme increased health care service utilisation and decreased OOP for the participants of the VHI and HSHI programmes. Therefore, the government should continue to consider improving the HI system as a strategy to achieve universal health coverage.

\section{Introduction}

Universal health coverage (UHC), which means that everyone can access sufficient quality health care services, including promotive, preventive, curative, rehabilitative, and palliative services without any financial difficulties, is a widely used concept, especially in low- and middleincome countries (LMIC) [1-5]. The World Health Organization is guiding LMIC to develop a health financing system to achieve and maintain UHC, where the national HI system has been promoted as a vital health financing strategy to expand pooled funds for equitable financing of health care [2].
Vietnam has achieved remarkable results in health care, reflected in some basic health indicators: the average life expectancy is 73 , infant mortality rate per 1,000 live births is 14.7 , maternal mortality rate per 1,000 live births is 54 , malnutrition rate of children under the age of 5 is $14.1 \%$, proportion of fully vaccinated children is $90 \%$, and the share of population with access to improved sanitation facilities is $75 \%[6,7]$. However, in recent years, there has been an increase in inequity in health between different regions and ethnic and income groups [8]. For example, the percentage of children who had an episode of diarrhoea among ethnic minority households is 2.8 times higher than that among Kinh/Hoa households. The corresponding figures for the 
lowest and highest quintile households are 5.2\% and $15.4 \%$, respectively [9]. Inequality in human resources for health also exists. The number of doctors per 10,000 people in the capital city is 9, but in remote areas, this figure is 1 [10]. The number of doctors at the grassroots level is 1,995 , while at the provincial level, it is 5,304 . The numbers of nurses with high degrees at these facilities are 140 and 1,920, respectively. The percentage of commune health stations with doctors is only $78 \%$ [6].

The Vietnamese government has made significant efforts to scale up public financial resources allocated to health to achieve UHC. The current health expenditure accounted for $6 \%$ of the gross domestic product in 2017, which was similar to those of neighbouring countries and other LMIC, such as China (5\%), Cambodia (6\%), Myanmar (5\%), and the Philippines (4\%). The per capita public expenditure on health (in purchasing power parity international dollar) increased from 69 in 2005 to 183 in 2017 [11], surpassing the benchmark of 86 set by the World Health Organization (WHO) [12]. However, Vietnam has moved away from certain benchmarks to achieve UHC. For example, the share of government health expenditure in the gross domestic product has fluctuated around 3\% during the last decade [11]. According to the WHO guidelines, if this share is less than $5 \%$, the health system depends significantly on out-ofpocket health expenditure (OOP) $[12,13]$. The proportion of OOP in the current health expenditure in Vietnam remains higher than those of Thailand, China, and Malaysia [11] (Figure 1). About 45\% of the total health expenditure originates from OOP, while the benchmark proposed by the WHO is $15 \%-20 \%$. This means that it is difficult to achieve the target of UHC when OOP constitutes more than $20 \%$ of the total health expenditure. The share of public health spending (state budget and social HI) experienced a significant decline from $58 \%$ in 2005 to $50 \%$ in 2017 (Figure 2). Additionally, government health expenditure as a share of total government spending remained stable at around 9\% [11]. The share of OOPs in total health spending, therefore, increased substantially from $37 \%$ to $45 \%$ between 2005 and 2017.

The impact of HI on the utilisation of health care services and OOP in LMIC is demonstrated by several published studies. Most studies postulate a positive impact of $\mathrm{HI}$ on health care utilisation [14-22]. For example, using the difference-in-difference (DID) method and data from health utilisation and expenditure surveys, Gotsadze et al. find that medical insurance for the poor in Georgia increased the use of formal health services by $12 \%$ [16]. Similarly, applying the fixed-effects model with instrumental variables, Liu and Zhao show that subsidised voluntary public HI programmes in China increased outpatient care utilisation by $7 \%-13 \%$ and the number of hospitalised days by $0.35-0.5$ days [18]. Erlangga et al. also investigate that Jaminan Kesehatan Nasional in Indonesia increased inpatient admission for the premium voluntarily paid group by $8.2 \%$ and subsidised group by $1.8 \%$ [21]. Similarly, in Vietnam, Nguyen finds that student and free HI programmes increased the number of health care visits by $12.4 \%$ and $66.1 \%$, respectively [23]. Guindon also suggests that the Health Care Fund for the

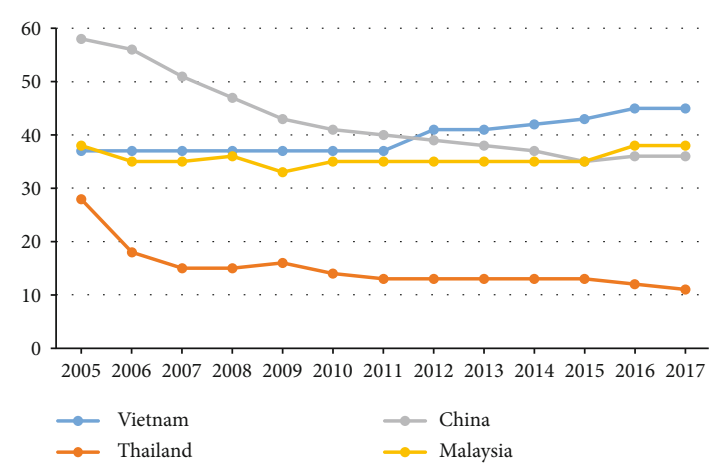

Figure 1: OOP as \% of the current health expenditure in select Asia Pacific countries [11].

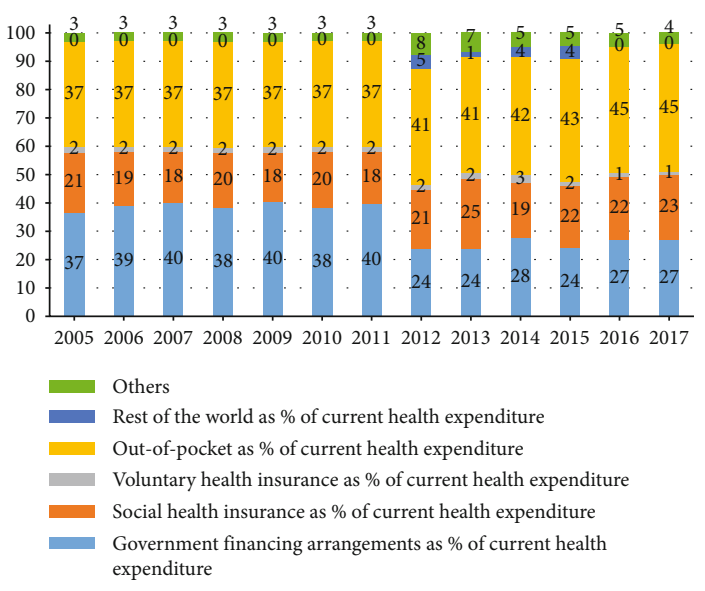

FIGURE 2: Structure of health financing resources, 2005-2017 [11].

Poor in Vietnam contributed to an increase of 0.068 in the number of inpatient visits [22].

However, evidence on the effect of $\mathrm{HI}$ on OOP reduction is inconsistent $[14,15,24-26]$. Many recent studies have shown that HI lowers OOP [16, 26-28]. However, Liu and Zhao find that the Urban Resident Basic Medical Insurance in China does not reduce OOP [18]. Another study in China indicates that the elderly participating in social $\mathrm{HI}$ spend more on total OOP than those without HI [29]. Additionally, Erlangga finds that the public HI programme in Indonesia has no statistically significant effect on OOP [30]. In Vietnam, while Axelson et al. demonstrate a negative effect of Vietnam's Health Care Fund for the Poor on OOP [31], Wagstaff shows that the Health Care Fund does not decrease OOP [32]. Nguyen confirms that the Free Health Insurance Programme for children aged under six reduces OOP per visit, whereas voluntary student HI programmes do not [23]. These contradictory results can be explained by the fact that these studies are conducted in different health settings with different HI policies and periods.

After the Vietnamese government passed the Revised HI Law in 2014, little quantitative evaluation has been conducted on the impacts of HI programmes on health care utilisation and OOP. This study-among the first to demonstrate these cause-effect relationships-is expected 


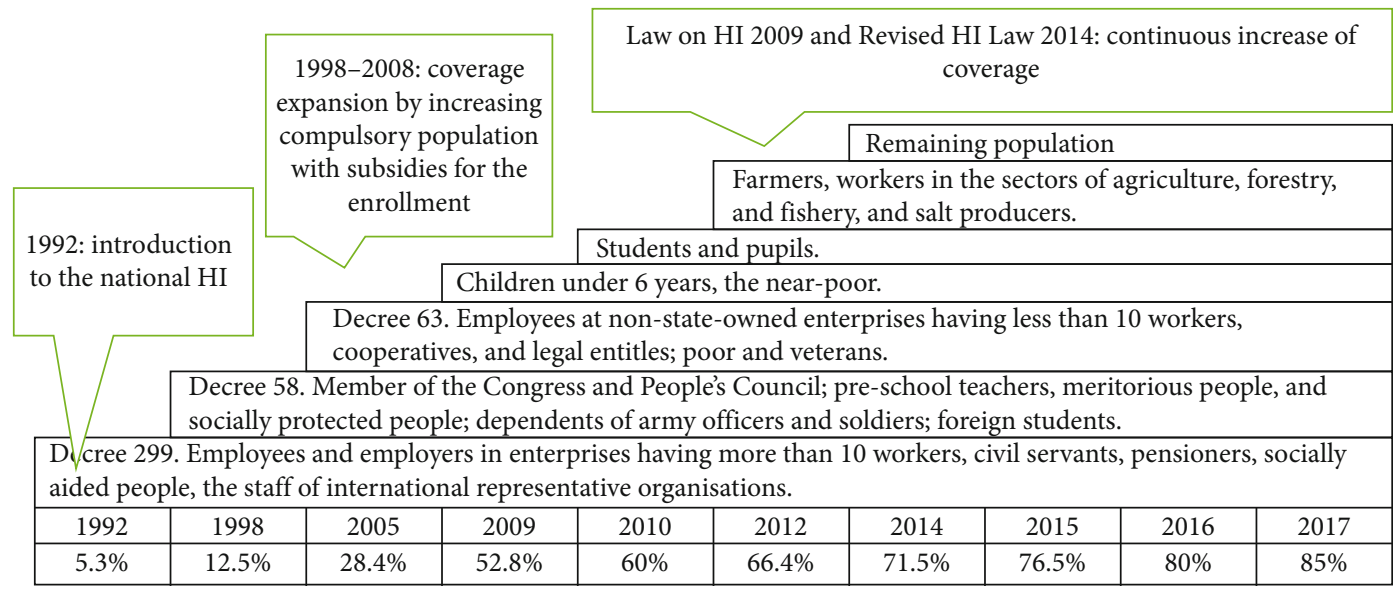

FIGURE 3: HI coverage expansion, 1992-2017 [34, 35].

to contribute to empirical evidence in the following aspects. First, we reveal empirical findings on the impact of HI on groups that pay a premium based on family. This familybased health insurance programme, also known as VHI, has been recently introduced in Vietnam and has not been assessed in previous studies. Second, one of the most important recent health financing reforms of the Vietnamese government has been the swap from supply-side to demandside subsidies, which is reflected in increasing the state budget to pay HI premium for the poor, near-poor, and other disadvantaged groups [33]. Therefore, evaluating the impact of HI on heavily subsidised groups can also provide important empirical evidence for policymakers in Vietnam. Third, to date, in Vietnam, far too little attention has been paid to examining the impact of $\mathrm{HI}$ on health care utilisation and OOP at different levels of health care providers. Fourth, the study uses more recent nationwide Vietnam Household Living Standard Surveys (VHLSS) 2014 and 2016. Therefore, the findings from these nationally representative data can be generalised to the whole population. Furthermore, regarding the health financing system, Vietnam and several LMIC share the same characteristics [34]. Hence, studying the performance of the HI scheme in terms of increasing access to health care services and reducing OOP can offer valuable experience to LMIC of moving toward UHC. Thus, this study is aimed at evaluating the impact of the HI schemes on health care utilisation and OOP using panel data from VHLSS 2014 and VHLSS 2016.

Overview of Vietnam's HI Programme. The process of implementing universal HI in Vietnam has achieved considerable results with rapidly increasing HI coverage (Figure 3). The HI policy was first introduced in Vietnam in 1992, aiming at covering civil servants and employees in large- and medium-sized private enterprises. In 1993 (after one year of implementing the policy), the number of people covered by $\mathrm{HI}$ accounted for only 5.3\% of the population; by 2017, this figure increased to approximately $85 \%$ [35] because, over the past 25 years, the government adopted several policies to expand HI coverage, removed financial barriers, and boosted access to health care services. In 2002, the government issued Decision 139, which established the Health Care
Fund for the Poor [36]. In 2005, Decree 63 was adopted, which included some compulsory enrolment groups, such as workers in nonstate enterprises with less than 10 employees and workers in all organisations that are legally established and operating. Besides, under the decree, full subsidies for purchasing $\mathrm{HI}$ cards for the poor and ethnic minorities were provided. Consequently, the share of the population with $\mathrm{HI}$ increased sharply from $28.4 \%$ in 2005 to $42 \%$ in 2007 [35]. In 2009, the HI Law was enacted, forming a national/social HI scheme. According to the law, individuals formally employed, children under the age of six, elderly, poor, and near-poor were the compulsory HI-covered groups [36]. Some groups received heavy subsidies from the Vietnamese government, resulting in the enrolment rate increasing to about $60 \%$ in 2010 [36].

In 2014, the Vietnamese government enacted the Revised HI Law [37] and the National Assembly passed Decree $105 / 2014 /$ ND-CP Guidance on implementing the HI Law [38], which stipulated the eligible groups of the population, premium contributions, subsidy levels from the state budget, determined copayment rates, and the participant's benefits. The law was officially effective from 1 January 2015. Vietnam Social Security is responsible for managing HI funds. In principle, Vietnam's HI scheme applies a single payer with a single financing pool and integrated benefits package [36]. According to the Revised HI Law, the HI scheme has been classified into five groups, in which, family-based contributions to HI premium have been added as group 5 [39]. Enrolment in HI is based on the individual and not the household level. This means that within a household, members might join different HI programmes with diverse premiums and subsidy levels and be entitled to several copayment rates. According to the revised law, HI membership is compulsory in Vietnam [37]. However, the government has been facing challenges when monitoring and compelling informal sector workers to participate. Consequently, the HI scheme in Vietnam continues to be a blend of compulsory and voluntary programmes [40].

In terms of HI coverage structure by entitlement groups, groups with full or partial subsidies from the government constituted the highest proportion of enrolees, accounting for $70 \%$ of the total enrolments (Figure 4) [41]. 


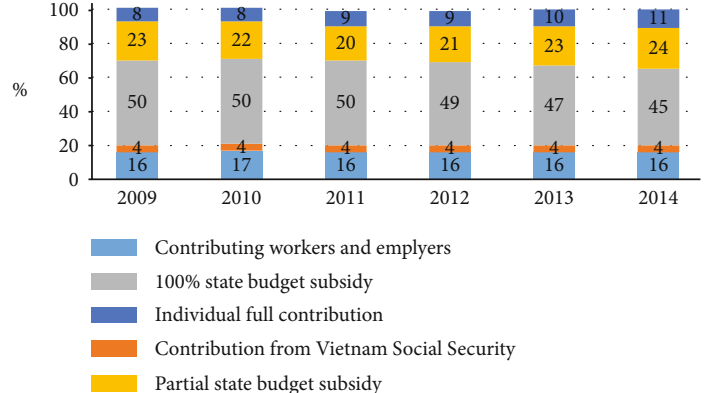

Figure 4: Trends and structure of HI coverage by entitlement groups, 2009-2014 [41].

In terms of benefit packages, $\mathrm{HI}$ includes curative and preventive health care services: medical examination, treatment, functional rehabilitation, pregnancy checkups and delivery, screening, and early diagnosis of some diseases [37], except for primary health care services covered by national target programmes, such as vaccination, counselling, education and health promotion, surveillance and prevention of infectious diseases, and maternal and child health care $[36,40]$. Health facilities covered by HI include the public and a small number of select private facilities having contracts with Vietnam Social Security [40]. The benefits packages were revised according to the HI Law 2014 and the entitlements extended for the enrolees, for example, covering costs of transporting patients from district hospitals to higher levels for some entitlement groups. Besides, the law now stipulates that the insured can visit any health facility at the district and commune levels without referring to letters [37, 40, 41]. The copayment rates were adjusted; for instance, the poor, ethnic minorities, policy beneficiaries (e.g., war veterans), people living in socioeconomically difficult areas, and islands are exempted from copayment and are entitled to free medical services; the copayment rate for the nearpoor reduced from $20 \%$ to $5 \%[37,39,40]$. With regard to provider payment methods, in Vietnam, there are three types of payment mechanisms: fee-for-service (the most popular method), capitation (applied mainly at district hospitals), and case-based or diagnostic-related groups (piloted in some provinces).

\section{Methods}

2.1. Data. We used data from the two recent rounds of VHLSS 2014 and 2016, which were carried out by the General Statistics Office of Vietnam and the World Bank. This is a large-scale national survey, representative of the whole country, rural and urban areas. While the 2014 survey covered 9,399 households and 35,920 individuals from 3,130 communes, the 2016 survey consisted of 35,793 individuals from 9,399 households, of whom 50\% were the same households selected from the VHLSS 2014 and 50\% were newly selected from the 2009 Census on Population and Housing of Vietnam. After matching two waves of VHLSS 2014 and VHLSS 2016, we obtained a balanced panel dataset comprising 30,180 observations from 15,090 individuals over 2 years.
The surveys included information on the types of HI cover of individuals, their health-seeking behaviour (i.e., the number of visits at different levels of health care providers-commune health centres, district hospitals, provincial hospitals, state and private health facilities, and traditional healers), and OOP reported in the last 12 months by interviewees. In addition, useful information on demographics and socioeconomic characteristics, such as age, gender, education, marital status, occupation status, household composition, expenditure and income, and region of residence, were included in the surveys.

2.2. Empirical Approach. The challenge in the empirical study is the need to create counterfactual evidence when addressing selection bias to evaluate the impact of a programme or intervention. As there may be a systematic heterogeneity between participants and nonparticipants with regard to their observed and unobserved characteristics, a direct outcome comparison among the insured and noninsured individuals can be biased. We applied the DID method and a combination of the propensity score matching (PSM) and DID methods to evaluate the impact of $\mathrm{HI}$ on OOP. The DID method assumes heterogeneity, which is not observed in the state of participation, but this factor is constant over time.

DID compares the differences in outcomes over the period with outcomes observed in the preintervention baseline survey between the treatment and control groups. Let us assume that there are two periods $t=0$ and $t=1$, where 0 implies a period before the programme is implemented and 1 indicates a period after the programme implementation. Let $T$ be the treatment status, where $T_{1}=1$ indicates individuals who are beneficiaries of the HI programme (i.e., the treatment group) at $t=1$, whereas $T_{1}=0$ denotes individuals not receiving entitlement of $\mathrm{HI}$ policy (i.e., the control group). Let $Y_{t}^{\mathrm{T}}$ and $Y_{t}^{\mathrm{C}}$ be the corresponding outcomes for the treatment and control groups in time $t$, respectively. Let $X$ be a vector of observed characteristics of individuals and households. The DID method allows us to calculate the average impact of the programme as follows [22, 42]:

$$
\operatorname{DID}(X)=E\left(Y_{1}^{\mathrm{T}}-Y_{0}^{\mathrm{T}} \mid X, T_{1}=1\right)-E\left(Y_{1}^{\mathrm{C}}-Y_{0}^{\mathrm{C}} \mid X, T_{1}=0\right),
$$

The DID estimate can be derived from the regression model. Specifically, the estimating equation has the following form:

$$
\begin{aligned}
Y_{i t}=\alpha+\beta T_{i 1}+\gamma t+\delta\left(T_{i 1} t\right) & +\theta X_{i t}+u_{i}+\varepsilon_{i} \\
(t & =0,1 ; i=1, \cdots, n),
\end{aligned}
$$

where $\alpha, \beta, \gamma, \delta$, and $\theta$ are unknown parameters; $\alpha$ is a constant term; $\beta$ captures the permanent differences in outcomes between the two groups; $\gamma$ accounts for the combined effects of any time-variant unmeasured covariates (i.e., the group effect) but affects outcomes identically for the treatment and control groups (i.e., time trend common to both groups); $\delta$ is the coefficient on the interaction term reflecting the true effect of 
treatment (i.e., the average DID effect of the programme); $u_{i}$ represents characteristics that do not change over time and are not observed; and $\varepsilon_{i}$ is random error $[42,43]$.

The DID method is based on an important assumption-the parallel trend assumption. This means that without the programme, the trend of change in outcomes for both the treatment group (HI participants) and the control group (nonparticipants) is the same. In other words, the trend in the outcome among individuals without $\mathrm{HI}$ in the period after the Revised HI Law was introduced serves as a good counterfactual for what would have happened to the treatment group in the absence of treatment.

In observational studies, different econometric methods exist to control observed and unobserved characteristics that may influence participation in $\mathrm{HI}$ and potential outcomes. In this study, to estimate DID, we used ordinary least squares (OLS) regressions and fixed-effects regressions, where unobserved heterogeneity characteristics are controlled. Additionally, the combination of PSM and DID methods with panel data at individual and household levels was exploited, which allows us to reduce the risk of bias in the estimation. This combination can be found in the studies of Mebratie et al. [44], Balamiento [45], Gustafsson-Wright et al. [46], and Nguyen [14]. While unobserved confounders that are likely to affect the decision to participate in $\mathrm{HI}$ and outcomes of interest are not considered in the PSM method, DID and PSM combined with DID account for time-invariant unobserved confounders [47].

\subsection{Definition of Variables}

2.3.1. Treatment and Control Groups. We have two treatment groups - the individuals covered by the VHI programme in 2016 and uninsured in 2014 and those covered by HSHI programmes (e.g., HI for the poor, near-poor, policy beneficiaries, and free $\mathrm{HI}$ card for some disadvantaged groups) in 2016 and had no HI in 2014. The control group includes individuals who had no HI in both 2014 and 2016. The number of observations in the VHI and HSHI treatment groups is 1,648 and 896 , respectively. The number of observations in the control group is 4,770 .

2.3.2. Outcome Variables. These include probability of having outpatient visits and inpatient visits; the number of outpatient visits, inpatient visits, and total visits; the number of visits at the district hospital; the number of visits at the provincial hospital; probability of having outpatient OOP and inpatient OOP; OOP for outpatient care; inpatient admissions of individuals; and total OOP at different levels of health facilities for 12 months. OOP consists of spending on medication, treatment, checkups, consultation, diagnosis, medicines, and indirect medical expenditure, such as travelling, caring, accommodation, and allowances for physicians. We took the natural logarithm of the OOP outcome variables. We added one in OOP before taking the natural logarithm $(\ln (\mathrm{OOP}+1))$ when individuals reported zero OOPs [3].

2.3.3. Control Variables. These were the observed characteristics of individuals and households before and after introducing the Revised HI Law, which included age, gen- der, ethnicity, marital status, education level, occupation, household composition, access to clean water, toilet, expenditure and assets of household, reported health status of individuals, and geographical location. They are controlled to reduce selection bias. These variables were selected based on a review of several previous studies $[14,29,31,39,44$, 48-51]. The definitions of the variables used in the estimates are presented in Table 1 .

\section{Results}

3.1. Descriptive Analysis. The descriptive statistics of patterns in utilisation of health services at different health facilities for the treatment and control groups of interest is provided in Table 2. The mean number of visits is reported in Table 2 for individuals who had outpatient and/or inpatient visits in the last 12 months. Overall, between 2014 and 2016, the probability of having outpatient and inpatient visits and the utilisation of outpatient and inpatient services for treatment groups increased, whereas the probability of having outpatient and inpatient visits among the control group was almost stable at approximately 30.4 and $3.7 \%$, respectively. The number of outpatient visits among the control group also remained unchanged at approximately 2.2 times per person per year. Similarly, the use of health care services at the district hospitals increased significantly among the VHI and HSHI treatment groups. For instance, the number of visits at the district hospital among the insured of the HSHI treatment group increased from 0.451 times in 2014 to 0.763 times in 2016. While the enrolees of HSHI programmes visited the provincial hospitals more intensively, those of the VHI programme visited these health facilities less frequently. Besides, compared to inpatient care utilisation, the frequency of using outpatient health care was higher for both the insured and uninsured, ranging from 1.778 to 2.493 times per person in the last 12 months. The number of outpatient visits was the highest for the VHI group. The treatment groups tended to use inpatient services more intensively compared to the control group. For example, in 2016, the average number of inpatient admissions among the VHI treatment group was 0.355 times per year, while the figure for the control sample was only 0.152 times per year.

Table 3 presents descriptive statistics of OOP structure, including the probability of having outpatient and inpatient OOP, the means of OOP for outpatient visits, inpatient admissions, and total OOP in relation to the level of health providers for the treatment and control groups in the baseline year 2014 and follow-up year 2016. The means of OOP per person were quite high because we only calculated for individuals who used medical services in the past 12 months and had reported their health expenses.

The probability of having outpatient and inpatient OOP increased for both VHI and HSHI groups whereas the figures for the control group were stable at around $30 \%$ and $4 \%$, respectively. Among the VHI enrolees, the average total OOP was VND 2,341.90 (approximately US\$110.28) in 2014 and VND 3,059.87 (US\$138.11) in 2016, which was considerably higher than that of the control group, with mean OOP of VND 1,852.11 (US\$87.22) 
TABLE 1: Definition of variables in evaluating the impact of HI on out-of-pocket expenditure.

\begin{tabular}{|c|c|}
\hline Variables & Description \\
\hline \multicolumn{2}{|l|}{ Treatment status } \\
\hline Participation in VHI & $\begin{array}{l}\text { Whether the household member participates in VHI (equals } 1 \text { if yes/0 if he or she does not } \\
\text { participate in any HI programme) }\end{array}$ \\
\hline Participation in HSHI programmes & $\begin{array}{l}\text { Whether the household member participates in the HI programme for the poor, near-poor, policy } \\
\text { beneficiaries such as meritorious people (equals } 1 \text { if yes/0 if he or she does not participate in any HI } \\
\text { programmes) }\end{array}$ \\
\hline \multicolumn{2}{|l|}{ Outcome variables } \\
\hline $\begin{array}{l}\text { Probability of having outpatient } \\
\text { visits }\end{array}$ & $\begin{array}{l}\text { Probability of visiting any of the health facilities for outpatient care by an individual in the last } 12 \\
\text { months }\end{array}$ \\
\hline $\begin{array}{l}\text { Probability of having inpatient } \\
\text { visits }\end{array}$ & $\begin{array}{l}\text { Probability of visiting any of the health facilities for inpatient care by an individual in the last } 12 \\
\text { months }\end{array}$ \\
\hline Number of outpatient visits & Number of outpatient visits by an individual at any of the health facilities in the last 12 months \\
\hline Number of inpatient visits & Number of inpatient visits by an individual at any of the health facilities in the last 12 months \\
\hline Total visits & Total number of visits in the last 12 months \\
\hline $\begin{array}{l}\text { Number of visits at the district } \\
\text { hospital }\end{array}$ & Number of visits at district hospital by an individual in the last 12 months \\
\hline $\begin{array}{l}\text { Number of visits at the provincial } \\
\text { hospital }\end{array}$ & Number of visits at the provincial hospital by an individual in the last 12 months \\
\hline $\begin{array}{l}\text { Probability of having outpatient } \\
\text { OOP }\end{array}$ & Probability of making outpatient OOP by an individual in the last 12 months \\
\hline $\begin{array}{l}\text { Probability of having inpatient } \\
\text { OOP }\end{array}$ & Probability of making inpatient OOP by an individual in the last 12 months \\
\hline Outpatient OOP & OOP for outpatient care in the last 12 months \\
\hline Inpatient OOP & OOP for inpatient admission in the last 12 months \\
\hline Total OOP & OOP for outpatient and inpatient care in the last 12 months \\
\hline $\begin{array}{l}\text { OOP per visit at the district } \\
\text { hospital }\end{array}$ & OOP per visit at the district hospital in the last 12 months \\
\hline $\begin{array}{l}\text { OOP per visit at the provincial } \\
\text { hospital }\end{array}$ & OOP per visit at the provincial hospital in the last 12 months \\
\hline \multicolumn{2}{|l|}{ Explanatory variables } \\
\hline Age group & Age of household members/individual (ordinal variable) equals \\
\hline$\leq 30$ & 1 if the individual belongs to the age group equal or below 30 \\
\hline $31-40$ & 2 if the individual belongs to the age group $31-40$ \\
\hline $41-50$ & 3 if the individual belongs to the age group $41-50$ \\
\hline $51-60$ & 4 if the individual belongs to the age group 51-60 \\
\hline$\geq 61$ & 5 if the individual belongs to the age group equal to or above 60 \\
\hline Gender (male) & Gender of the individual ( 1 if male/0 if female) \\
\hline Ethnicity (Kinh and Hoa) & $\begin{array}{l}\text { Whether an individual belongs to ethnic Kinh/Hoa group (equals } 1 \text { if yes/ } 0 \text { if the individual belongs } \\
\text { to a different ethnic minority group) }\end{array}$ \\
\hline Marital status (married) & Marital status of the individual ( 1 if married/0 otherwise) \\
\hline Education level & The education level of the individual (ordinal variable) equals \\
\hline Not completed primary school & 1 if the individual did not finish primary school \\
\hline Primary school & 2 if the individual completed primary school \\
\hline Lower secondary & 3 if the individual completed lower secondary school \\
\hline Upper secondary & 4 if the individual completed upper secondary school \\
\hline Vocational school & 5 if the individual completed vocational school \\
\hline College, university, master, $\mathrm{PhD}$ & 6 if the individual completed college, university, master, $\mathrm{PhD}$ \\
\hline
\end{tabular}


TABLE 1: Continued.

\begin{tabular}{|c|c|}
\hline Variables & Description \\
\hline Occupation status & Occupation status of the individual (categorical variable) equals \\
\hline Professionals/technicians & 1 if the individual works as a professional or technician \\
\hline Service or sales staff & 2 if the individual works as a service or sales staff \\
\hline $\begin{array}{l}\text { Labourers in } \\
\text { agriculture/forestry/fishery }\end{array}$ & 3 if the individual works in agriculture or forestry or fishery \\
\hline $\begin{array}{l}\text { Manual labourers or machine } \\
\text { operators }\end{array}$ & 4 if the individual works as a manual labourer or machine operator \\
\hline Unskilled workers & 5 if the individual works as an unskilled worker \\
\hline Others & 6 if the individual does other jobs/or is not in the labour force \\
\hline Household size & Total household members (continuous variable) \\
\hline \multicolumn{2}{|l|}{ Household composition } \\
\hline Share of children below 6 years & Share of children below 6 years in the household (continuous variable) \\
\hline $\begin{array}{l}\text { Share of the elders above } 60 \\
\text { years }\end{array}$ & Share of the elders above 60 years in the household (continuous variable) \\
\hline Access to clear water & Whether the household has access to clean water ( 1 if yes/0 if no) \\
\hline Toilet access & Whether the household has access to a toilet ( 1 if yes/ 0 if no) \\
\hline Expenditure quintiles & $\begin{array}{l}\text { Based on household consumption expenditure data in the last } 12 \text { months, each individual in the } \\
\text { household was ranked by their score. The ranking was then divided into five equal parts, from } \\
\text { quintile one to quintile five. Each quintile group accounted for } 20 \% \text { of the sample. It is an ordinal } \\
\text { variable and equals }\end{array}$ \\
\hline $\begin{array}{l}\text { First expenditure quintile group } \\
\text { (poorest) }\end{array}$ & 1 if the individual belongs to the first expenditure quintile (poorest) \\
\hline $\begin{array}{l}\text { Second expenditure quintile } \\
\text { group }\end{array}$ & 2 if the individual belongs to the second expenditure quintile \\
\hline $\begin{array}{l}\text { Third expenditure quintile } \\
\text { group }\end{array}$ & 3 if the individual belongs to the third expenditure quintile \\
\hline $\begin{array}{l}\text { Fourth expenditure quintile } \\
\text { group }\end{array}$ & 4 if the individual belongs to the fourth expenditure quintile \\
\hline $\begin{array}{l}\text { Fifth expenditure quintile group } \\
\text { (richest) }\end{array}$ & 5 if the individual belongs to the fifth expenditure quintile (richest) \\
\hline Number of motorcycles & The number of motorcycles that household possesses (continuous variable) \\
\hline Number of telephones & The number of telephones that household possesses (continuous variable) \\
\hline $\begin{array}{l}\text { Number of radio, television, or } \\
\text { computer }\end{array}$ & The number of radio, television, or computer that household possesses (continuous variable) \\
\hline Total residential area $\left(\mathrm{m}^{2}\right)$ & The total residential area that household has (continuous variable) \\
\hline $\begin{array}{l}\text { Number of illness (times) in the } \\
\text { last } 12 \text { months }\end{array}$ & $\begin{array}{l}\text { Number of times that individual had an illness or severe injury in the last } 12 \text { months (continuous } \\
\text { variable) }\end{array}$ \\
\hline $\begin{array}{l}\text { Number of illness (days) in the } \\
\text { last } 12 \text { months }\end{array}$ & $\begin{array}{l}\text { Number of days that individual had an illness or severe injury in the last } 12 \text { months (continuous } \\
\text { variable) }\end{array}$ \\
\hline Place of residence (urban) & Whether an individual lives in an urban area ( 1 if yes/ 0 if he or she lives in a rural area) \\
\hline Region & The region where individual lives (categorical variable). It equals \\
\hline Red River Delta & 1 if the individual lives in the Red River Delta region \\
\hline $\begin{array}{l}\text { Northern Midlands and } \\
\text { Mountains }\end{array}$ & 2 if the individual lives in the Northern Midlands and Mountains \\
\hline North and South Central Coast & 3 if the individual lives in North and South Central Coast \\
\hline Central Highlands & 4 if the individual lives in Central Highlands \\
\hline South East & 5 if the individual lives in South East \\
\hline Mekong River Delta & 6 if the individual lives in Mekong River Delta \\
\hline
\end{tabular}

and VND 2,200 (US\$99.29) in 2014 and 2016, respectively. Regarding the participants of HSHI programmes, the average total OOP was also higher compared to the control group and experienced an increase between 2014 and 2016 with VND 2,029.96 (US\$95.59) and VND 2,328.69 (US\$105.10), respectively. 
TABLE 2: Descriptive statistics of health care utilisation across different samples in 2014 and 2016.

\begin{tabular}{|c|c|c|c|c|c|c|c|c|}
\hline \multirow{4}{*}{ Variables } & \multicolumn{8}{|c|}{ VHI } \\
\hline & \multicolumn{4}{|c|}{2014} & \multicolumn{4}{|c|}{2016} \\
\hline & \multicolumn{2}{|c|}{$\begin{array}{l}\text { Treated } \\
(N=824)\end{array}$} & \multicolumn{2}{|c|}{$\begin{array}{c}\text { Control } \\
(N=2,385)\end{array}$} & \multicolumn{2}{|c|}{$\begin{array}{c}\text { Treated } \\
(N=824)\end{array}$} & \multicolumn{2}{|c|}{$\begin{array}{c}\text { Control } \\
(N=2,385)\end{array}$} \\
\hline & Mean & $\mathrm{SD}$ & Mean & SD & Mean & SD & Mean & SD \\
\hline Probability of having outpatient visits & 0.320 & 0.467 & 0.304 & 0.460 & 0.434 & 0.495 & 0.308 & 0.461 \\
\hline Probability of having inpatient visits & 0.049 & 0.217 & 0.037 & 0.188 & 0.109 & 0.312 & 0.039 & 0.195 \\
\hline Number of outpatient visits & 2.422 & 3.519 & 2.218 & 2.714 & 2.493 & 3.637 & 2.312 & 2.336 \\
\hline Number of inpatient visits & 0.158 & 0.418 & 0.133 & 0.407 & 0.355 & 1.030 & 0.152 & 0.542 \\
\hline Total visits & 0.911 & 2.406 & 0.781 & 1.892 & 1.459 & 2.991 & 0.842 & 1.787 \\
\hline Number of visits at the district hospital & 0.351 & 1.061 & 0.327 & 0.880 & 0.867 & 3.151 & 0.281 & 0.941 \\
\hline Number of visits at the provincial hospital & 0.742 & 1.661 & 0.343 & 1.030 & 0.616 & 1.631 & 0.427 & 1.365 \\
\hline
\end{tabular}

\section{HSHI}

Variables

2014

\begin{tabular}{|c|c|}
\hline & \\
\hline $\begin{array}{l}\text { Control } \\
J=2,385)\end{array}$ & $\begin{array}{l}\text { Treated } \\
(N=448)\end{array}$ \\
\hline
\end{tabular}

\begin{tabular}{lcccccccc} 
& Mean & SD & Mean & SD & Mean & SD & Mean & SD \\
\hline Probability of having outpatient visits & 0.310 & 0.463 & 0.304 & 0.460 & 0.408 & 0.492 & 0.308 & 0.461 \\
Probability of having inpatient visits & 0.060 & 0.238 & 0.037 & 0.188 & 0.095 & 0.294 & 0.039 & 0.195 \\
Number of outpatient visits & 1.778 & 1.800 & 2.218 & 2.714 & 2.439 & 2.715 & 2.312 & 2.336 \\
Number of inpatient visits & 0.185 & 0.435 & 0.133 & 0.407 & 0.275 & 0.687 & 0.152 & 0.542 \\
Total visits & 0.710 & 1.389 & 0.781 & 1.892 & 1.254 & 2.268 & 0.842 & 1.787 \\
Number of visits at the district hospital & 0.451 & 1.115 & 0.327 & 0.880 & 0.763 & 1.665 & 0.281 & 0.941 \\
Number of visits at the provincial hospital & 0.259 & 0.541 & 0.343 & 1.030 & 0.522 & 1.616 & 0.427 & 1.365 \\
\hline
\end{tabular}

SD: standard deviation; $N$ : number of observations.

TABLe 3: Descriptive statistics of OOP across different samples in 2014 and 2016.

\begin{tabular}{|c|c|c|c|c|c|c|c|c|}
\hline \multirow{4}{*}{ Variables } & \multicolumn{8}{|c|}{ VHI } \\
\hline & \multicolumn{4}{|c|}{2014} & \multicolumn{4}{|c|}{2016} \\
\hline & \multicolumn{2}{|c|}{ Treated $(N=824)$} & \multicolumn{2}{|c|}{ Control $(N=2,385)$} & \multicolumn{2}{|c|}{ Treated $(N=824)$} & \multicolumn{2}{|c|}{ Control $(N=2,385)$} \\
\hline & Mean & SD & Mean & SD & Mean & SD & Mean & SD \\
\hline Probability of having outpatient OOP & 0.31 & 0.46 & 0.30 & 0.46 & 0.40 & 0.49 & 0.31 & 0.46 \\
\hline Probability of having inpatient OOP & 0.05 & 0.22 & 0.04 & 0.19 & 0.10 & 0.30 & 0.04 & 0.19 \\
\hline Outpatient OOP & 1186.15 & 2207.17 & 985.33 & 1865.84 & 1135.34 & 2682.71 & 1382.36 & 2965.20 \\
\hline Inpatient OOP & 8984.15 & 15717.05 & 8539.96 & 22330.11 & 9831.26 & 24224.66 & 8178.68 & 15779.14 \\
\hline Total OOP & 2341.90 & 6819.74 & 1852.11 & 8056.38 & 3059.87 & 11989.11 & 2200.01 & 6738.59 \\
\hline OOP per visit at the district hospital & 423.69 & 425.99 & 804.38 & 1441.37 & 681.68 & 1479.83 & 776.63 & 973.65 \\
\hline OOP per visit at the provincial hospital & 3729.94 & 8722.14 & 3348.49 & 9016.72 & 3374.31 & 5281.88 & 3991.41 & 8967.93 \\
\hline \multirow{4}{*}{ Variables } & \multicolumn{8}{|c|}{ HSHI } \\
\hline & \multicolumn{4}{|c|}{2014} & \multicolumn{4}{|c|}{2016} \\
\hline & \multicolumn{2}{|c|}{ Treated $(N=448)$} & \multicolumn{2}{|c|}{ Control $(N=2,385)$} & \multicolumn{2}{|c|}{ Treated $(N=448)$} & \multicolumn{2}{|c|}{ Control $(N=2,385)$} \\
\hline & Mean & $\mathrm{SD}$ & Mean & SD & Mean & SD & Mean & SD \\
\hline Probability of having outpatient OOP & 0.31 & 0.46 & 0.30 & 0.46 & 0.35 & 0.48 & 0.31 & 0.46 \\
\hline Probability of having inpatient OOP & 0.06 & 0.24 & 0.04 & 0.19 & 0.09 & 0.29 & 0.04 & 0.19 \\
\hline Outpatient OOP & 928.47 & 1316.48 & 985.33 & 1865.84 & 1326.01 & 4197.43 & 1382.36 & 2965.20 \\
\hline Inpatient OOP & 7399.82 & 11255.55 & 8539.96 & 22330.11 & 5566.98 & 7514.78 & 8178.68 & 15779.14 \\
\hline Total OOP & 2029.96 & 5283.36 & 1852.11 & 8056.38 & 2328.69 & 5828.10 & 2200.01 & 6738.59 \\
\hline OOP per visit at the district hospital & 1254.97 & 2672.46 & 804.38 & 1441.37 & 673.78 & 1750.07 & 776.63 & 973.65 \\
\hline OOP per visit at the provincial hospital & 5605.29 & 10117.52 & 3348.49 & 9016.72 & 3448.19 & 5830.04 & 3991.41 & 8967.93 \\
\hline
\end{tabular}

SD: standard deviation; N: number of observations. Exchange rate in 2014: VND 21,235 = US\$1 and in 2016: VND 22,156 = US $\$ 1$. 
Among the treatment groups, the VHI group had higher total OOP than the HSHI group in both years (VND 2,341.9 and 3,059.8 vs. VND 2,029.9 and 2,328.6). Increased OOP trends for outpatient visits were observed in both the treatment and control groups. In particular, the insured of the HSHI group experienced a pronounced increase from VND 928.07 (US\$43.70) to VND 1,326.01 (US\$59.85) between 2014 and 2016. While the OOP for inpatient admissions was significantly reduced for the HSHI groups from VND 7,399.82 (US\$348.47) in 2014 to VND $5,566.98$ (US\$251.26) in 2016, this trend was not visible among the participants of the VHI.

Table 3 also provides information on the average OOP per visit at different levels of health care providers for the treatment and control samples. Generally, patients spent much more when using health services at a higher level of providers. The average OOP per visit at the district hospital of the comparison groups ranged from VND 423.69 to VND 1,254.97 (US\$19.95 to US\$56.64), while OOP per visit at the provincial hospital was considerably higher, between VND 3,348.49 (US\$157.69) and VND 5,605.29 (US\$252.99). The OOP per visit at provincial hospitals significantly decreased for both the VHI and HSHI groups, while it considerably increased for the control group. Also, the OOP per visit at district hospitals sharply decreased for the HSHI sample.

Several observable and unobservable variables can influence the differences in OOP among the enrolees and nonenrolees. Table 4 provides summary statistics of the characteristics of the insured and noninsured before and after the Revised HI Law was introduced. Compared to nonenrolees, those covered by VHI were as follows: generally older, less likely to be males, unskilled workers, more likely to live in households with a high proportion of people above 60 years, have access to clean water and toilet, live in households with higher expenditure, and possess more assets, such as motorcycles, telephones, radios, televisions, and computers. Further, they were more likely to be ill a greater number of times and for a higher number of days in the last 12 months.

Table 4 also represents descriptive statistics of the observable characteristics of the HSHI group. Overall, compared to individuals without HI, participants of HSHI programmes were more likely to be elderly, ethnic minorities, less educated, unskilled workers, and live in households with a higher share of the elderly and less likely to have access to toilet. Further, they were more likely to be the poorest, have fewer assets, such as motorcycles, telephones, radios, televisions, and computers, a lower health status, and live in rural areas.

3.2. Impact of HI on the Utilisation of Health Care Services. Table 5 reports the estimates of the impact of the VHI and HSHI programmes on probability of having visits and changes in individuals' utilisation of health services. DID and combination of PSM and DID (PSM-DID) methods with panel data of 2014 and 2016 were applied for impact assessment. Overall, the HI programmes had statistically positive impacts on the utilisation of health care services.

The results of the DID method show that enrolment in the VHI and HSHI programmes increased the probability of having outpatient visits by around 5\%. The VHI programme also increased the probability of seeking inpatient care among the insured by $2 \%$. In addition, participation in the VHI and HSHI programmes was significantly associated with an increase of about $0.178-0.286$ in the mean number of total visits per person per year. The magnitude of the impact of the VHI programme was larger $(0.284$ vs. 0.178 under pooled OLS estimates). The study also examines the impact of HI on the use of outpatient and inpatient health care services separately. We found that the VHI and HSHI programmes significantly increased the mean number of outpatient visits by 0.172 and 0.293 in the last 12 months, respectively. However, the $\mathrm{HI}$ scheme had no statistically significant impact on the mean number of inpatient admissions. The average treatment effect also shows that an increase between 0.339 and 0.342 in the mean number of visits at district hospitals was due to VHI enrolment, whereas the average treatment effect of HSHI programmes on the mean number of visits at district hospitals was lower, at about 0.258 annually. In addition, the results suggest that enrolling in the VHI programme led to an increase of approximately $0.167-0.179$ in the mean number of visits at provincial hospitals. However, the results show that HI did not have any statistically significant impact on the number of visits at the provincial hospital for those participating in the HSHI scheme. When comparing the treatment groups who sought care at district and provincial hospitals, the results indicate that the size of impact for the former was larger than that of the latter.

Consistent with DID estimates, the PSM-DID estimates also demonstrate a positive impact of the VHI and HSHI programmes on the probability of seeking outpatient and inpatient care and utilisation of health care services. In comparison with DID, the estimates of the effect of HSHI on the number of outpatient visits and the total number of visits obtained using PSM-DID were higher (0.241 vs. 0.172 and 0.217 vs. 0.178 , respectively). By contrast, the estimates of the impact of HSHI on the number of visits at the district hospitals under the PSM-DID method were smaller compared to the DID method (Table 5).

3.3. Impact of HI on OOP. Estimates of the impact of HI on OOP indicators of household members, including probability of having OOP, OOPs for outpatient visits, inpatient admissions, and at different health facilities are presented in Table 6. Across different treatment groups, the estimates demonstrated significant reductions in the OOP on outpatient care and total OOP, although the size of the impact of $\mathrm{HI}$ on the VHI group was larger than that on the HSHI group. Because we used a semilogarithmic regression equation for estimating the impact of HI reform on OOPs, this impact was calculated as follows: $e^{\beta}-1$ [3].

Under the DID method, the results indicated that compared to the control group, the VHI group had approximately $3.8 \%$ and $1.4 \%$ higher probabilities of having outpatient and inpatient OOP, respectively. Similarly, HSHI programmes increased the probability of having outpatient OOP by $3.7 \%$. However, the HSHI scheme was not found to impact the probability of having inpatient OOP. On the 
TABle 4: Descriptive statistics of control variables.

\begin{tabular}{|c|c|c|c|c|c|c|c|c|c|c|c|c|}
\hline \multirow[t]{2}{*}{ Variable } & \multicolumn{2}{|c|}{$\begin{array}{l}\text { Control } \\
\text { group }\end{array}$} & \multicolumn{2}{|c|}{$\begin{array}{l}\text { Treatment } \\
\text { group } \\
\text { (VHI) }\end{array}$} & \multicolumn{2}{|c|}{$\begin{array}{c}\text { Treatment } \\
\text { group } \\
(\mathrm{HSHI})\end{array}$} & \multicolumn{2}{|c|}{$\begin{array}{l}\text { Control } \\
\text { group }\end{array}$} & \multicolumn{2}{|c|}{$\begin{array}{l}\text { Treatment } \\
\text { group } \\
\text { (VHI) }\end{array}$} & \multicolumn{2}{|c|}{$\begin{array}{l}\text { Treatment } \\
\text { group } \\
\text { (HSHI) }\end{array}$} \\
\hline & Mean & $\mathrm{SD}$ & Mean & $\mathrm{SD}$ & Mean & $\mathrm{SD}$ & Mean & $\mathrm{SD}$ & Mean & SD & Mean & SD \\
\hline \multicolumn{13}{|l|}{ Age group } \\
\hline$\leq 30$ (ref.) & 0.04 & 0.22 & 0.02 & 0.21 & 0.05 & 0.23 & 0.43 & 0.47 & 0.41 & 0.46 & 0.41 & 0.47 \\
\hline $31-40$ & 0.22 & 0.41 & 0.17 & 0.38 & 0.18 & 0.38 & 0.16 & 0.36 & 0.11 & 0.31 & 0.11 & 0.31 \\
\hline $41-50$ & 0.34 & 0.47 & 0.35 & 0.48 & 0.32 & 0.47 & 0.18 & 0.39 & 0.16 & 0.36 & 0.15 & 0.36 \\
\hline $51-60$ & 0.25 & 0.44 & 0.28 & 0.45 & 0.25 & 0.43 & 0.13 & 0.33 & 0.18 & 0.39 & 0.15 & 0.36 \\
\hline$\geq 61$ & 0.15 & 0.36 & 0.18 & 0.38 & 0.20 & 0.40 & 0.10 & 0.30 & 0.14 & 0.34 & 0.18 & 0.38 \\
\hline Gender (male) & 0.51 & 0.50 & 0.47 & 0.50 & 0.50 & 0.50 & 0.51 & 0.50 & 0.46 & 0.50 & 0.51 & 0.50 \\
\hline Ethnicity (Kinh, Hoa) & 0.97 & 0.16 & 0.98 & 0.15 & 0.88 & 0.32 & 0.97 & 0.17 & 0.98 & 0.15 & 0.88 & 0.33 \\
\hline Marital status (married) & 0.79 & 0.41 & 0.79 & 0.41 & 0.75 & 0.43 & 0.79 & 0.40 & 0.81 & 0.39 & 0.74 & 0.44 \\
\hline \multicolumn{13}{|l|}{ Education level } \\
\hline Not completed primary school (ref.) & 0.20 & 0.43 & 0.18 & 0.42 & 0.31 & 0.46 & 0.18 & 0.45 & 0.17 & 0.47 & 0.28 & 0.44 \\
\hline Primary school & 0.30 & 0.46 & 0.28 & 0.45 & 0.28 & 0.45 & 0.31 & 0.46 & 0.29 & 0.45 & 0.30 & 0.46 \\
\hline Lower secondary & 0.33 & 0.47 & 0.32 & 0.47 & 0.30 & 0.46 & 0.32 & 0.47 & 0.31 & 0.46 & 0.30 & 0.46 \\
\hline Upper secondary & 0.11 & 0.32 & 0.14 & 0.35 & 0.08 & 0.27 & 0.11 & 0.31 & 0.13 & 0.34 & 0.06 & 0.24 \\
\hline Vocational school & 0.05 & 0.22 & 0.06 & 0.24 & 0.03 & 0.16 & 0.06 & 0.23 & 0.08 & 0.27 & 0.05 & 0.21 \\
\hline College, university, master, $\mathrm{PhD}$ & 0.01 & 0.12 & 0.02 & 0.13 & 0.00 & 0.07 & 0.02 & 0.13 & 0.02 & 0.15 & 0.01 & 0.11 \\
\hline \multicolumn{13}{|l|}{ Occupation status } \\
\hline Professionals/technicians (ref.) & 0.01 & 0.08 & 0.01 & 0.08 & 0.00 & 0.05 & 0.01 & 0.08 & 0.01 & 0.10 & 0.01 & 0.08 \\
\hline Service and sales staff & 0.15 & 0.36 & 0.19 & 0.39 & 0.07 & 0.26 & 0.16 & 0.37 & 0.19 & 0.40 & 0.07 & 0.26 \\
\hline Labourers in agriculture/forestry/fishery & 0.10 & 0.30 & 0.11 & 0.31 & 0.15 & 0.35 & 0.08 & 0.27 & 0.11 & 0.31 & 0.14 & 0.35 \\
\hline Manual labourers and machine operators & 0.21 & 0.41 & 0.18 & 0.38 & 0.12 & 0.33 & 0.22 & 0.42 & 0.22 & 0.42 & 0.15 & 0.36 \\
\hline Unskilled workers & 0.44 & 0.50 & 0.38 & 0.49 & 0.51 & 0.50 & 0.44 & 0.50 & 0.35 & 0.48 & 0.49 & 0.50 \\
\hline Others & 0.10 & 0.30 & 0.14 & 0.35 & 0.15 & 0.36 & 0.09 & 0.28 & 0.12 & 0.32 & 0.14 & 0.35 \\
\hline Household size & 4.25 & 1.37 & 4.24 & 1.48 & 4.33 & 1.67 & 4.22 & 1.44 & 4.24 & 1.55 & 4.21 & 1.80 \\
\hline \multicolumn{13}{|l|}{ Household composition } \\
\hline Share of children below 6 years & 0.08 & 0.13 & 0.07 & 0.11 & 0.08 & 0.13 & 0.08 & 0.12 & 0.07 & 0.12 & 0.08 & 0.12 \\
\hline Share of the elders above 60 years & 0.09 & 0.18 & 0.11 & 0.21 & 0.15 & 0.28 & 0.10 & 0.20 & 0.13 & 0.23 & 0.17 & 0.30 \\
\hline Access to clear water & 0.79 & 0.41 & 0.86 & 0.34 & 0.80 & 0.40 & 0.79 & 0.41 & 0.85 & 0.36 & 0.80 & 0.40 \\
\hline Toilet access & 0.64 & 0.48 & 0.76 & 0.43 & 0.44 & 0.50 & 0.72 & 0.45 & 0.81 & 0.39 & 0.54 & 0.50 \\
\hline \multicolumn{13}{|l|}{ Expenditure quintiles } \\
\hline First expenditure quintile group (poorest) (ref.) & 0.22 & 0.42 & 0.15 & 0.40 & 0.32 & 0.45 & 0.16 & 0.36 & 0.09 & 0.35 & 0.23 & 0.42 \\
\hline Second expenditure quintile group & 0.25 & 0.43 & 0.23 & 0.42 & 0.26 & 0.44 & 0.22 & 0.41 & 0.17 & 0.38 & 0.22 & 0.41 \\
\hline Third expenditure quintile group & 0.21 & 0.41 & 0.26 & 0.44 & 0.16 & 0.37 & 0.24 & 0.43 & 0.22 & 0.42 & 0.22 & 0.41 \\
\hline Fourth expenditure quintile group & 0.17 & 0.38 & 0.18 & 0.39 & 0.16 & 0.37 & 0.20 & 0.40 & 0.27 & 0.44 & 0.23 & 0.42 \\
\hline Fifth expenditure quintile group (richest) & 0.15 & 0.35 & 0.18 & 0.39 & 0.10 & 0.30 & 0.18 & 0.38 & 0.25 & 0.44 & 0.10 & 0.30 \\
\hline Number of motorcycles & 1.36 & 0.79 & 1.50 & 0.84 & 1.16 & 0.82 & 1.49 & 0.81 & 1.57 & 0.83 & 1.20 & 0.87 \\
\hline Number of telephones & 1.75 & 1.02 & 1.90 & 1.07 & 1.49 & 1.02 & 1.92 & 1.10 & 2.07 & 1.14 & 1.58 & 0.96 \\
\hline Number of radio, television, or computer & 1.18 & 0.52 & 1.29 & 0.64 & 1.06 & 0.43 & 1.21 & 0.59 & 1.34 & 0.65 & 1.09 & 0.48 \\
\hline Number of illness (times) in last 12 months & 0.05 & 0.37 & 0.08 & 0.37 & 0.11 & 0.38 & 0.07 & 0.43 & 0.24 & 0.85 & 0.22 & 0.74 \\
\hline Number of illness (days) in last 12 months & 0.67 & 9.51 & 1.17 & 7.33 & 2.00 & 9.88 & 0.74 & 5.30 & 3.18 & 13.08 & 2.00 & 7.14 \\
\hline Place of residence (urban) & 0.26 & 0.44 & 0.26 & 0.44 & 0.14 & 0.34 & 0.26 & 0.44 & 0.26 & 0.44 & 0.14 & 0.34 \\
\hline
\end{tabular}


TABLe 4: Continued.

\begin{tabular}{|c|c|c|c|c|c|c|c|c|c|c|c|c|}
\hline \multirow[t]{2}{*}{ Variable } & \multicolumn{2}{|c|}{$\begin{array}{l}\text { Control } \\
\text { group }\end{array}$} & \multicolumn{2}{|c|}{$\begin{array}{l}\text { Treatment } \\
\text { group } \\
\text { (VHI) }\end{array}$} & \multicolumn{2}{|c|}{$\begin{array}{c}\text { Treatment } \\
\text { group } \\
(\mathrm{HSHI})\end{array}$} & \multicolumn{2}{|c|}{$\begin{array}{l}\text { Control } \\
\text { group }\end{array}$} & \multicolumn{2}{|c|}{$\begin{array}{l}\text { Treatment } \\
\text { group } \\
\text { (VHI) }\end{array}$} & \multicolumn{2}{|c|}{$\begin{array}{l}\text { Treatment } \\
\text { group } \\
\text { (HSHI) }\end{array}$} \\
\hline & Mean & $\mathrm{SD}$ & Mean & $\mathrm{SD}$ & Mean & $\mathrm{SD}$ & Mean & $\mathrm{SD}$ & Mean & $\mathrm{SD}$ & Mean & SD \\
\hline \multicolumn{13}{|l|}{ Region } \\
\hline Red River Delta (ref.) & 0.26 & 0.42 & 0.26 & 0.43 & 0.17 & 0.36 & 0.26 & 0.44 & 0.26 & 0.43 & 0.17 & 0.38 \\
\hline Northern Midlands and Mountains & 0.08 & 0.27 & 0.10 & 0.30 & 0.15 & 0.35 & 0.08 & 0.27 & 0.10 & 0.30 & 0.15 & 0.35 \\
\hline North and South Central Coast & 0.20 & 0.40 & 0.25 & 0.43 & 0.38 & 0.48 & 0.20 & 0.40 & 0.25 & 0.43 & 0.38 & 0.48 \\
\hline Central Highlands & 0.07 & 0.26 & 0.05 & 0.22 & 0.08 & 0.27 & 0.07 & 0.26 & 0.05 & 0.22 & 0.08 & 0.27 \\
\hline South East & 0.12 & 0.33 & 0.12 & 0.33 & 0.05 & 0.23 & 0.12 & 0.33 & 0.12 & 0.33 & 0.05 & 0.23 \\
\hline Mekong River Delta & 0.27 & 0.44 & 0.22 & 0.42 & 0.17 & 0.38 & 0.27 & 0.44 & 0.22 & 0.42 & 0.17 & 0.38 \\
\hline
\end{tabular}

SD: standard deviation.

whole, HI had a statistically significant negative impact on outpatient OOP. The estimated results of the pooled OLS and fixed-effects specification were quite similar. The impact was more pronounced for the HSHI group. The policy lowered outpatient OOP for individuals participating in HSHI programmes by $34.2 \%\left(\left(e^{-0.418}-1\right) \times 100\right)$ compared with $25.2 \%\left(\left(e^{-0.291}-1\right) \times 100\right)$ for enrolees of VHI (columns 2 and 4 of Table 6). Similarly, the HI decreased OOP for participants of the VHI and HSHI programmes when they sought inpatient care services. Nevertheless, a statistically significant impact was only found for the VHI group. Inpatient OOP for the participants of VHI decreased by $41.4 \%$ and $43.2 \%$ under the pooled OLS and fixed-effects specifications, respectively. Overall, the HI scheme reduced the total OOP for the participants of VHI and HSHI, ranging from $19.8 \%$ to $30.8 \%$. In terms of the health provider's level, we found that the HI considerably reduced OOP for the insured of the VHI and HSHI groups when they used health services at the district hospitals. The percentages of reduction were $72.3 \%$ for the former and $63.2 \%$ for the latter under the fixed-effects estimate. With regard to visiting provincial hospitals, while the HI scheme contributed to decreases of $32.1 \%$ in OOPs for the VHI group (column 1 of Table 6), the impact of HI was not statistically significant for the HSHI group. Among the insured of the VHI programme, the HI reform lowered OOP more for those using health care services at district hospitals than those visiting provincial hospitals with $70.9 \%$ and $32.1 \%$, respectively (the last two rows of Table 6).

In the PSM-DID method, the patterns of the impact of HI on OOPs were generally consistent with the DID method. Nevertheless, the impact of HSHI on the probability of having outpatient OOP was quite higher under the PSM-DID method than under the DID method. Compared to the estimation results of DID, using the PSM-DID method yielded a higher impact of VHI and a lower impact of HSHI programmes on OOP for outpatient care. Under the DID estimates, the HI policy contributed to the reduction of $25.2 \%$ and $34.2 \%$ in outpatient OOP for the VHI and HSHI groups, respectively. However, the figures were $29.0 \%$ and $25.5 \%$ when applying the PSM-DID method (columns 2, 4, 6, and 8 of Table 6). Similarly, although HI policy's negative impacts on OOP for inpatient admissions were observed for both the VHI and HSHI groups, the statistically significant effect was only found in the VHI sample. Similar to results of the DID method, the HI scheme reduced OOP per visit at provincial hospitals by as much as $31.7 \%$ for the participants of VHI (column 5 of Table 4), and the HI policy did not statistically affect OOP of HSHI enrolees when they sought care at provincial hospitals.

\section{Discussion and Conclusion}

This study evaluates the impact of the HI programmes on health care utilisation and OOP in Vietnam using panel data from VHLSS 2014 and VHLSS 2016. To solve the problem of self-selection when citizens participate in $\mathrm{HI}$ and control for unobserved confounders, we used the DID method to determine the causal impact of the HI programme. Our major results indicate that the VHI and HSHI programmes increased the incidence of outpatient and inpatient visits and the utilisation of medical services and reduced OOP among the insured. The results indicate that HI significantly increased the probability of individuals having outpatient care and the utilisation of outpatient care and lowered OOP for outpatient care for both the VHI and HSHI groups. This effect remained the same under different specifications. Changes in HI policy can explain the increase in outpatient care utilisation and reduction in OOP; for example, cost sharing for the poor decreased from $5 \%$ to $0 \%$, and that for the near-poor reduced from $20 \%$ to $5 \%$. Besides, the insured do not have to incur copayment when they receive any medical examination and treatment at the commune level or when the cost per visit is lower than $15 \%$ of the basic salary [37, 40]. This finding broadly supports the work of other studies in evaluating the impact of $\mathrm{HI}$ on health care utilisation. Most studies demonstrate that HI significantly increased the number of health care visits $[14,16$, $18,21]$. For example, it has been shown by Nguyen that participation in VHI results in a significant increase in the average number of outpatient visits by approximately 0.9137 [14]. In terms of reducing OOP, our estimation result is consistent with that of Sepehri et al. [3]. Using fixed-effects 


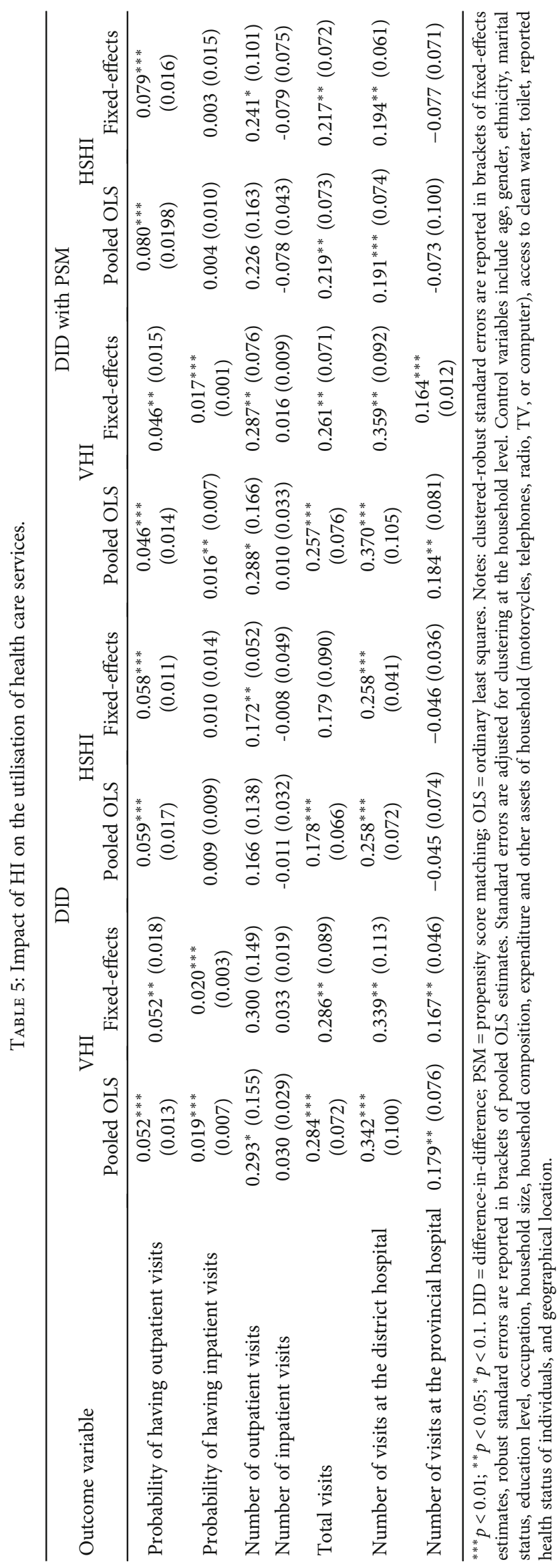




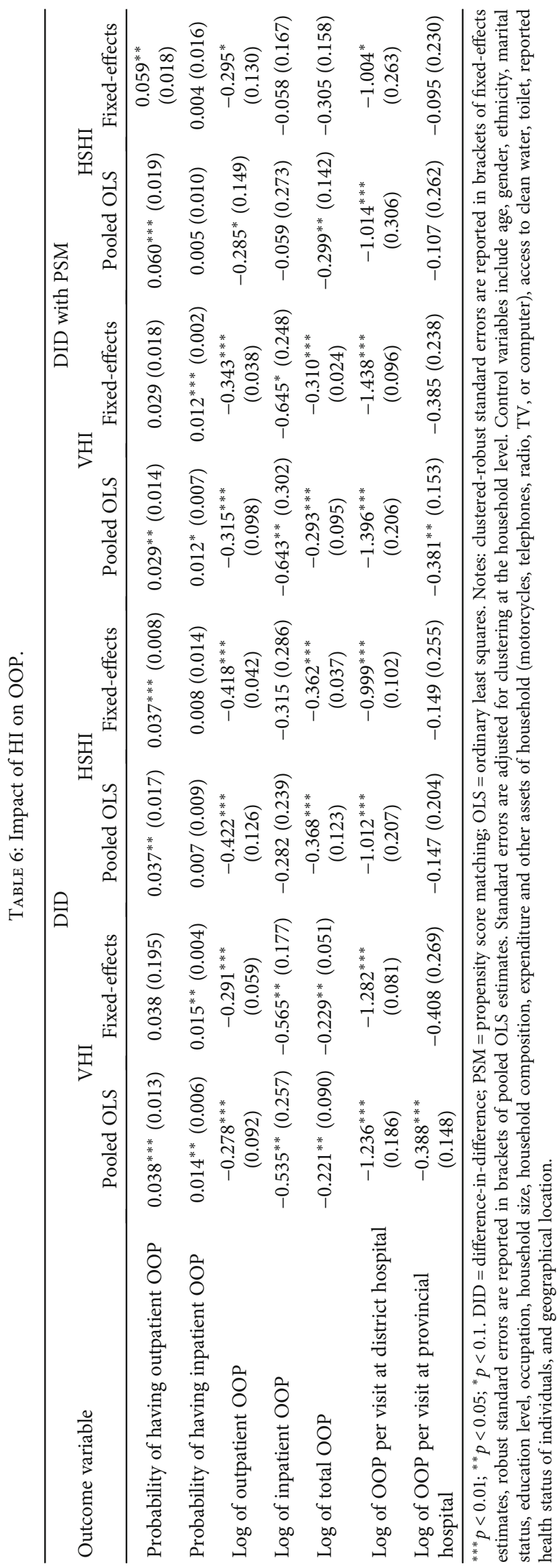


and random-effects models, they show that $\mathrm{HI}$ in Vietnam reduced OOP by $24 \%$ for VHI participants and $15 \%$ for participants of HI for the poor. These findings were also reported by Wagstaff [15]. Using the DID method, the author found that Vietnam's Health Care Fund for the Poor considerably reduced OOP. Additionally, Aji et al. found that $\mathrm{HI}$ for the poor and vulnerable groups (Askeskin) in Indonesia lowered OOP by $34 \%$ [24]. However, the result is contrary to that of Nguyen, who found that there was no statistically significant impact of VHI on OOP [14]. A possible explanation for this difference is that Nguyen used the VHLSS 2004 and VHLSS 2006 datasets. After the Revised HI Law was introduced in 2014, there was a difference in the entitlements for VHI participants [40].

Furthermore, the impact of the HI programme on OOP for inpatient admission was negative, although the estimates were only statistically significant for the VHI group. The reduction in inpatient OOP and the increase in the number of inpatient visits for those participating in the VHI programme suggest that the HI scheme in Vietnam has improved. No evidence that the HSHI programmes had reduced inpatient OOP might be related to the fact that there was no statistically significant impact of the HSHI programmes on the probability of hospitalisation and the intensity of using inpatient care among the insured. Besides, two waves of the VHLSS (2014 and 2016) might be a short period for $\mathrm{HI}$ to impact inpatient OOP. Several reasons can also explain no reduction in OOP for hospital admission among the HSHI enrolees. No cap on copayment spending is a significant contributory factor for high OOP among inpatients. Quality of care in Vietnam has improved; therefore, patients might seek high-tech services and imported drug brands for treatment, subject to high OOP [36]. Besides, the fee-forservice payment method, which is commonly applied in hospitals in Vietnam, motivates health care providers to oversupply services [40, 52, 53]. Therefore, the Ministry of Health and Vietnam Social Security could flexibly apply payment methods. For example, capitation should be implemented for outpatient care and case-based payment for inpatient treatment at district hospitals; case-based payment methods can also be applied to inpatient treatment in all state hospitals except for high-tech facilities. Besides, strengthening control of drug and pharmaceutical prices, reducing the copayment for the use of generic drugs to change patients' preference for expensive drugs, and stimulating the consumption of generic drugs should be priorities. Promotion is also needed to eliminate prejudice against locally produced and generic drugs. Additionally, the limitation in understanding insurance entitlements can make inpatients pay more in copayment than they should [36]. Further research is needed to explain the reasons for the estimation results more fully.

This study also found that participation in HI increased the health care utilisation and reduced OOP of both the VHI and HSHI groups when they visited a district hospital. This study supports evidence from previous observations of [3]. In addition, the HI programmes had a higher impact on health care utilisation at the district level than at the provincial level. It may be that these participants benefitted from the free cost of examination and treatment. In fact, before the Revised HI was enacted, the insured received $70 \%$ of reimbursement for inpatient admission and paid full medical cost for outpatient care if they visited a district hospital without a referral. However, after the enactment of the Revised HI Law, the insured can skip referral and seek inpatient care at any district hospital without bearing additional copayment [37, 40].

With regard to the provincial hospital level of care, this study indicated that the VHI enrolment increased the number of visits. In addition, participation in VHI lowered OOP. However, the impact of the HI programme on health care utilisation and OOP in the HSHI group was not significant. A possible explanation for this result might be due to the following: medical and nonmedical payments; physical barriers; and quality, attitude, and behaviours of health care providers toward the insured of the HSHI group, which may prevent them from accessing this level of care [36, 54-56]. Another possible explanation for the insignificant impact is the way we defined OOP to include not only user fees but also informal payments, such as bonuses for physicians, spending on additional medicines, and equipment/supplies. However, HI reimbursed only user fees and list of drugs.

Thus, the government could develop a policy of full exemption of copayment for the near-poor to reduce their OOP. In fact, the threshold for dividing the poor and nearpoor is not substantially different. In addition, policymakers should develop policies for free patient transportation from district health facilities to higher levels of care and free meals for disadvantaged groups when they visit provincial hospitals. To protect households from massive OOP, the government could also introduce a threshold copayment policy. This means that patients do not have to copay if their monthly payment has attained a particular threshold. Furthermore, the Ministry of Health could improve the quality of medical care by issuing practice certificates, professional ethics, quality accreditation, and clinical practice guidelines, addressing unreasonable use of medicine problems via guidance on medical care practices.

\section{Limitations}

There are some limitations to this study. First, there could be measurement errors in the VHLSS surveys used. Some questions were based on self-reporting by interviewees, such as the number of outpatient and inpatient visits, the number of visits at health facilities in the past 12 months, OOP for outpatient care, and inpatient admissions, which can lead to inevitable and differential recall biases. Second, the variables used in the econometric model mainly address the demand-side. The variables that address the supply-side and the external environment, such as the number of health facilities and health workers, availability of drugs in every commune or district, local budgets for health, epidemic diseases, local disease control, natural disasters, environmental pollution, and local socioeconomic conditions, should be investigated in future research. Although we used panel data and a fixed-effects method to eliminate time-invariant 
unobserved characteristics, the bias cannot be removed entirely. Third, due to time and budget constraints, we could not conduct in-depth interviews to assess the impact of qualitative factors, such as attitudes of health staff, the insured patients, and the noninsured's satisfaction with medical services on health care utilisation as well as service providers' perceptions, views of local authorities, and policymakers. Such primary data could have helped create deeper insights into stakeholders' views and reduce potential evaluation bias. We believe that future research will fill this gap. Finally, the interval after the revision of the law may have been short to evaluate its impact. Future research may address these issues by using longitudinal data.

\section{Data Availability}

Data are available on request through the corresponding author (nttthuong@tueba.edu.vn).

\section{Conflicts of Interest}

The authors declare that they have no conflicts of interest.

\section{References}

[1] S. Prinja, P. Bahuguna, I. Gupta, S. Chowdhury, and M. Trivedi, "Role of insurance in determining utilization of healthcare and financial risk protection in India," PLoS One, vol. 14, no. 2, article e0211793, 2019.

[2] R. Pokharel and P. R. Silwal, "Social health insurance in Nepal: a health system departure toward the universal health coverage," The International Journal of Health Planning and Management, vol. 33, no. 3, pp. 573-580, 2018.

[3] A. Sepehri, S. Sarma, and U. Oguzoglu, "Does the financial protection of health insurance vary across providers? Vietnam's experience," Social Science \& Medicine, vol. 73, no. 4, pp. 559-567, 2011.

[4] K. Obermann, M. Jowett, and S. Kwon, "The role of national health insurance for achieving UHC in the Philippines: a mixed methods analysis," Global Health Action, vol. 11, no. 1, article 1483638, 2018.

[5] S. Prinja, G. Kaur, R. Gupta, S. K. Rana, and A. K. Aggarwal, "Out-of-pocket expenditure for health care: district level estimates for Haryana state in India," The International Journal of Health Planning and Management, vol. 34, no. 1, pp. 277293, 2019.

[6] Vietnam Ministry of Health, Health Statistics Yearbook, Medical publisher, Ha Noi, Vietnam, 2017.

[7] Vietnam Ministry of Health, "Joint annual health review 2016. Towards healthy aging in Vietnam," Ha Noi, Vietnam, 2018.

[8] Partnership for Action in Health Equity, "Health system in Vietnam: toward targets with equity, partnership for action in health equity," 2013.

[9] General Statistics office Viet Nam and UNICEF, "Monitoring the situation of children and women. Viet Nam Multiple Indicator Cluster Survey," Ha Noi, Vietnam, 2014.

[10] Wise Consulting Finland Oy, "My health emerging markets," Wise Consulting Finland Oy, Vietnam, 2017.

[11] World Health Organization, "Global Health Expenditure Database," 2020, June 2020, http://apps.who.int.
[12] M. Jowett, M. P. Brunal, G. Flores, and J. Cylus, "Spending targets for health: no magic number," World Health Organization, Geneva, Switzerland, 2016.

[13] D. McIntyre and J. Kutzin, "Health financing country diagnostic: a foundation for national strategy development," No. WHO/HIS/HGF/HFDiagnostics/16.1, World Health Organization, 2016.

[14] C. V. Nguyen, "The impact of voluntary health insurance on health care utilization and out-of-pocket payments: new evidence for Vietnam," Health Economics, vol. 21, no. 8, pp. 946-966, 2012.

[15] A. Wagstaff, "Estimating health insurance impacts under unobserved heterogeneity: the case of Vietnam's health care fund for the poor," Health Economics, vol. 19, no. 2, pp. 189208, 2010.

[16] G. Gotsadze, A. Zoidze, N. Rukhadze, N. Shengelia, and N. Chkhaidze, "An impact evaluation of medical insurance for poor in Georgia: preliminary results and policy implications," Health Policy and Planning, vol. 30, Supplement 1, pp. i2-i13, 2015.

[17] P. A. Dalinjong, P. Welaga, J. Akazili et al., "The association between health insurance status and utilization of health services in rural Northern Ghana: evidence from the introduction of the National Health Insurance Scheme," Journal of Health, Population and Nutrition, vol. 36, no. 1, p. 42, 2017.

[18] H. Liu and Z. Zhao, "Does health insurance matter? Evidence from China's urban resident basic medical insurance," Journal of Comparative Economics, vol. 42, no. 4, pp. 1007-1020, 2014.

[19] G. Chen, G. G. Liu, and F. Xu, "The impact of the urban resident basic medical insurance on health services utilisation in China," PharmacoEconomics, vol. 32, no. 3, pp. 277-292, 2014.

[20] X. Li and W. Zhang, "The impacts of health insurance on health care utilization among the older people in China," Social Science \& Medicine, vol. 85, pp. 59-65, 2013.

[21] D. Erlangga, S. Ali, and K. Bloor, "The impact of public health insurance on healthcare utilisation in Indonesia: evidence from panel data," International Journal of Public Health, vol. 64, no. 4, pp. 603-613, 2019.

[22] G. E. Guindon, "The impact of health insurance on health services utilization and health outcomes in Vietnam," Health Economics, Policy, and Law, vol. 9, no. 4, pp. 359-382, 2014.

[23] C. Nguyen, "The impact of health insurance programs for children: evidence from Vietnam," Health Economics Review, vol. 6, no. 1, p. 34, 2016.

[24] B. Aji, M. De Allegri, A. Souares, and R. Sauerborn, "The impact of health insurance programs on out-of-pocket expenditures in Indonesia: an increase or a decrease?," International Journal of Environmental Research and Public Health, vol. 10, no. 7, pp. 2995-3013, 2013.

[25] A. Acharya, S. Vellakkal, E. Masset, A. Satija, M. Burke, and S. Ebrahim, "Systematic review. Impact of national health insurance for the poor and the informal sector in low-and middle-income countries," The EPPI-Centre, London, 2012.

[26] D. Erlangga, M. Suhrcke, S. Ali, and K. Bloor, "The impact of public health insurance on health care utilisation, financial protection and health status in low- and middle-income countries: a systematic review," PLoS One, vol. 14, no. 8, article e0219731, 2019.

[27] D. Levine, R. Polimeni, and I. Ramage, "Insuring health or insuring wealth? An experimental evaluation of health 
insurance in rural Cambodia," Journal of Development Economics, vol. 119, pp. 1-15, 2016.

[28] E. W. Kanmiki, A. A. Bawah, J. F. Phillips et al., "Out-ofpocket payment for primary healthcare in the era of national health insurance: evidence from northern Ghana," PLoS One, vol. 14, no. 8, article e0221146, 2019.

[29] Z. Wang, X. Li, M. Chen, and L. Si, "Social health insurance, healthcare utilization, and costs in middle-aged and elderly community-dwelling adults in China," International Journal for Equity in Health, vol. 17, no. 1, p. 17, 2018.

[30] D. Erlangga, "The impact evaluation of public health insurance in Indonesia on access to care, financial protection, and health status," University of York, 2018.

[31] H. Axelson, S. Bales, P. Minh, B. Ekman, and U. G. Gerdtham, "Health financing for the poor produces promising short-term effects on utilization and out-of-pocket expenditure: evidence from Vietnam," International Journal for Equity in Health, vol. 8, no. 1, p. 20, 2009.

[32] A. Wagstaff, Health Insurance for the Poor: Initial Impacts of Vietnam's Health Care Fund for the Poor, World Bank, Washington, DC, 2007.

[33] The World Bank, World Health Organization and UNICIEF, "Moving toward UHC: Vietnam. National initiatives, key challenges, and the role of collaborative activities," 2017.

[34] M. Matsushima, H. Yamada, and Y. Shimamura, "Analysis on demand - and supply - side responses during the expansion of health insurance coverage in Vietnam: challenges and policy implications toward universal health coverage," Review of Development Economics, vol. 24, no. 1, pp. 144-166, 2020.

[35] General Statistics Office, "Social insurance, health insurance and unemployment insurance," June 2020, https://www.gso .gov.vn/.

[36] A. Somanathan, A. Tandon, H. L. Dao, K. L. Hurt, and H. L. Fuenzalida-Puelma, Moving toward Universal Coverage of Social Health Insurance in Vietnam: Assessment and Options, World Bank, Washington DC, 2014.

[37] The National Assembly, "Law amendments to the law on health insurance. No: 46/2014/QH13,” pp. 4-17, 2014.

[38] Government of Vietnam, "Decree 105/2014/NĐ-CP Guidance on implementing Health Insurance Law," 2015.

[39] R. Hasegawa, "Factors influencing enrolment in Vietnamese National Health Insurance: evidence from six provinces in 2018," The International Journal of Health Planning and Management, vol. 35, no. 1, pp. e108-e118, 2019.

[40] Japan International Cooperation Agency (JICA) and KRI International Corp, "Basic information survey for basic health service package and provider payment mechanism in Viet Nam.," 2017.

[41] Vietnam Ministry of Health and Health Partnership Group, "Joint Annual Health Review 2015. Strengthening primary health care at the grassroots towards universal health coverage," 2016.

[42] S. R. Khandker, G. B. Koolwal, and H. A. Samad, Handbook on Impact Evaluation: Quantitative Methods and Practices, The World Bank, Washington, DC, 2010.

[43] C. Wing, K. Simon, and R. A. Bello-Gomez, "Designing difference in difference studies : best practices for public health policy research," Annual Review of Public Health, vol. 39, no. 1, pp. 453-469, 2018.

[44] A. D. Mebratie, R. Sparrow, Z. Yilma, D. Abebaw, G. Alemu, and A. S. Bedi, "The impact of Ethiopia's pilot community based health insurance scheme on healthcare utilization and cost of care," Social Science \& Medicine, vol. 220, pp. 112119, 2019.

[45] N. C. Balamiento, "The impact of social health insurance on healthcare utilization outcomes: evidence from the Indigent Program of the Philippine National Health Insurance," International Institute of Social Studies, Erasmus, 2018.

[46] E. Gustafsson-Wright, G. Popławska, Z. Tanović, and J. van der Gaag, "The impact of subsidized private health insurance and health facility upgrades on healthcare utilization and spending in rural Nigeria," International Journal of Health Economics and Management, vol. 18, no. 3, pp. 221-276, 2018.

[47] P. J. Gertler, S. Martinez, P. Premand, L. B. Rawlings, and C. M. Vermeersch, Impact Evaluation in Practice, Inter-American De velopment Bank and World Bank, Washington, DC, second edition edition, 2016.

[48] M. Adane, B. Mengistie, W. Mulat, H. Kloos, and G. Medhin, "Utilization of health facilities and predictors of healthseeking behavior for under-five children with acute diarrhea in slums of Addis Ababsa, Ethiopia: a community-based cross-sectional study," Journal of Health, Population and Nutrition, vol. 36, no. 1, p. 9, 2017.

[49] H. Zhao, "China's health insurance reform and disparities in healthcare utilization and costs: a longitudinal analysis," Pardee RAND Graduate School, 2014.

[50] Y.-. H. Lee, Y.-. C. Chang, and M. Shelley, "Is preventive care utilization associated with lower outpatient and inpatient health-care expenses among Chinese older adults? A longitudinal analysis," The International Journal of Health Planning and Management, vol. 35, no. 1, pp. e142-e155, 2019.

[51] S. Jing, A. Yin, L. Shi, and J. Liu, "Whether new cooperative medical schemes reduce the economic burden of chronic disease in rural China," PLoS One, vol. 8, no. 1, article e53062, 2013.

[52] H. Van Minh, N. T. K. Phuong, P. Saksena, C. D. James, and $\mathrm{K} . \mathrm{Xu}$, "Financial burden of household out-of pocket health expenditure in Viet Nam: findings from the National Living Standard Survey 2002 -2010," Social Science \& Medicine, vol. 96, pp. 258-263, 2013.

[53] H. Nguyen, R. Ivers, S. Jan, and C. Pham, "Analysis of out-ofpocket costs associated with hospitalised injuries in Vietnam," BMJ Global Health, vol. 2, no. 1, article e000082, 2017.

[54] N. Le, W. Groot, S. M. Tomini, and F. Tomini, "Health insurance and patient satisfaction: evidence from the poorest regions of Vietnam, No. 040," United Nations University-Maastricht Economic and Social Research Institute on Innovation and Technology (MERIT), 2018.

[55] B. X. Tran, L. H. Nguyen, V. M. Nong, and C. T. Nguyen, "Health status and health service utilization in remote and mountainous areas in Vietnam," Health and Quality of Life Outcomes, vol. 14, no. 1, p. 85, 2016.

[56] K. Takashima, K. Wada, T. T. Tra, and D. R. Smith, "A review of Vietnam's healthcare reform through the Direction of Healthcare Activities (DOHA)," Environmental Health and Preventive Medicine, vol. 22, no. 1, p. 74, 2017. 